\title{
Os sentidos do diagrama nos processos de pesquisa em arte : como tornar o mundo matéria-prima para a criação
}

The diagram's senses in the research processes of art: how to make the world raw material for creation.

Claudia Marinho, Marcio Peixoto \& José Antonio da Silva Filho.

\section{Diagrama. Pesquisa. Arte. Espaço}

O presente artigo aborda o diagrama como esquema de visualização dos processos estéticosinvestigativos que envolvem a produção de referências na pesquisa em artes. Os conceitos documento de processo e inscrição são os pontos de partida para buscar aproximações entre as materialidades das práticas investigativas da arte e da ciência e fundamentos para a realização de experimentações estéticas-metodológicas a partir do uso de ferramentas digitais de visualização de dados, tendo em vista a proposta de refletir sobre as práticas investigativas do artista como estratégia de espacialização de conhecimentos e dos gráficos (diagramas) como instrumentos de cognição e comunicação na construção de esquemas investigativos.

\section{Diagram. Research. Art. Space.}

The present article approaches the production reference in the processes of research in art from the production of diagrams. The concepts document process and inscription are driven to think an approach of the processes of research in art for a bias not only representational and the forms of connections between projective resources and poetic propositions. As a strategy, it starts from an approach of the diagram as a technical apparatus of mediation between the multiple steps involved in the processes of creation and research in the arts and the accomplishment of methodological experiments of the uses of graphs - diagrams - from the use of digital tools of visualization of Data, to reflect on ways of spatializing knowledge and building new research schemes.

\section{Apresentação}

Com este artigo, relatamos processos de investigação e experimentação metodológica dos usos de gráficos - diagramas - como aparato de mediação entre as múltiplas etapas implicadas em processos de criação e pesquisa em artes. $\mathrm{Na}$ adoção destes percursos, como processos de produção de conhecimento e prática projetiva, propomos abordar os diagramas como estratégias para a espacialização de conhecimentos, instrumentos de cognição e comunicação na construção de esquemas investigativos.

As experimentações trazidas aqui, aplicadas em diferentes works in progress, são o resultado de discussões realizadas na disciplina Ateliê de Criação, integrante curricular Programa de Pós-Graduação em Artes - PPGArtes, da Universidade Federal do Ceará - UFC. A partir das distintas proposições trazidas ao longo do artigo, buscamos uma aplicação do pensamento diagramático e a utilização dos diagramas não apenas como estratégias de pesquisa, mas também como recurso poético. Mais adiante discorremos sobre as singularidades de cada proposição, suas respectivas dramaturgias, seus percursos de investigação e como os gráficos emergem, em cada contexto, como recurso visual e estratégico para o processo de pesquisa em artes.

Anais do 9 CIDI e 9 CONGIC

Luciane Maria Fadel, Carla Spinillo, Anderson Horta,

Cristina Portugal (orgs.)

Sociedade Brasileira de Design da Informação - SBDI

Belo Horizonte | Brasil | 2019

ISBN 978-85-212-1728-2
Proceedings of the 9th CIDI and 9th CONGIC

Luciane Maria Fadel, Carla Spinillo, Anderson Horta,

Cristina Portugal (orgs.)

Sociedade Brasileira de Design da Informação - SBDI

Belo Horizonte | Brazil | 2019

ISBN 978-85-212-1728-2 
O diagrama é um recurso amplamente empregado em diferentes áreas de conhecimento para o registro, acompanhamento e condução de processos, e aqui, para além disso, como técnica de criação para a visualização de relações espaciais e temporais, no cruzamento das informações das pesquisas em andamento. Este cenário pode ser compreendido pela expressão virada icônica - iconic turn; termo empregado por Bonsiepe (2007), ao identificar, como consequência das inovações tecnológicas - especialmente em tecnologia digital - a relativização da primazia da discursividade como domínio privilegiado da cognição: o termo virada icônica significa o reconhecimento do plano visual como um domínio cognitivo em contraste com a tradição centenária do verbo-centrismo.

Uma característica da arte contemporânea é a crescente investida de artistas em estratégias advindas de outros campos de conhecimento - da filosofia às ciências humanas, exatas ou biológicas - evidenciando uma ampliação e complexificação das redes que compõem as práticas criativas do artista contemporâneo, nas quais podemos incluir a própria invenção de métodos que permitem aos artistas/pesquisadores uma apropriação dos saberes de outras áreas, de acordo com os propósitos de seus respectivos e singulares processos. Esse exercício de produção metodológica consiste em abordar projetos de pesquisa em andamento ${ }^{1}$ pelo viés das estratégias do diagrama. Dessa forma, no tocante do artigo, recorremos às ferramentas de autoria de visualização de dados para criar meta-processos (a meta como um objetivo de movimento), para operar a transposição das múltiplas dimensões de fenômenos específicos - trazidos pelas proposições das pesquisas - transformados em matéria-prima para a criação, a partir de operações de redução e deslocamento. Os conhecimentos técnicos e conceituais engendrados nos diagramas - artífices metodológicos do design da informação e também conceito da filosofia - são incorporados aos processos das pesquisas relatadas no artigo a partir de um movimento de apropriação criativa de suas estratégias, pautado inicialmente pela imprecisão.

Apreende-se na prática que o desenvolvimento de um processo artístico envolve a construção de uma materialidade que ancore as proposições dos projetos em questão, haveria, portanto, uma expansão dos terrenos de atuação do artista em direção a territórios não determinados a priori; um deslocamento por entre códigos, áreas e campos de pesquisa, modos de misturar para compor novas redes; dentre os quais privilegiamos o design da informação.

O artigo está estruturado em duas seções. A primeira seção apresenta as discussões que envolvem o tema central do artigo, a produção de referência de pesquisa na arte e a noção de diagrama como estratégia de pesquisa. A segunda seção apresenta os resultados das experimentações realizadas.

\section{Produção de referência e registro de processos}

Essa discussão se assenta em uma questão clássica nos estudos da filosofia, da arte e da ciência: como acondicionar o mundo em (na) linguagem? Para levar esta questão adiante, ancoramos as experimentações trazidas ao corpo deste artigo nos estudos de Cecília Salles (2008-2012) e Bruno Latour (2001), autores que, cada um em seu campo de pesquisa - arte e ciência - parecem encampar a discussão partindo de domínios diferentes, mas com estratégias semelhantes; as quais identificamos na articulação da noção de diagrama e o foco nos processos de produção de referências.

Antes, no entanto, é preciso pontuar que não partiremos de um conceito de pesquisa comum, partilhado na obra de ambos. Apoiado no ferramental da observação etnográfica, Latour emprega a meticulosa observação de campo para analisar os laboratórios de cientistas, por isso seus argumentos partem de um paradigma de pesquisa muito próximo do que se pode observar nas ciências exatas, ou nas naturais, em suas práticas laboratoriais, com a mediação de instrumentos, tecnologia e fundamentação lógico-matemática, ou ainda no uso de equipamentos sofisticados para a observação e quantificação de dados da natureza.

\footnotetext{
1 Pathos: Os diagramas como estratégias para uma cartografia afetiva, por Marcio Peixoto, e Mapa de Errâncias: $A$ persistência da imagem na cidade-dormitório, por José Antonio da Silva Filho.
} 
Cecília Salles, por sua vez, fazendo uso das estratégias oferecidas pela Crítica Genética, aborda os processos estruturantes do fazer artístico a partir da análise dos rastros deixados pelo artista durante o desenvolvimento de um projeto, os documentos de processo. Coloca em foco a pesquisa que é realizada e implicada no próprio processo de produção da obra de arte. A autora fala sobre um tipo de pesquisa realizada pelos próprios artistas em seu trabalho de compreensão de suas obras ou da arte em geral, a partir de uma demanda comunicativa existente no processo: de produção de diálogos de natureza inter e intrapessoal ao longo das cadeias que definem os sistemas de criação.

Ambas as noções não são opostas, mas complementares, refletem modos conscientes de obtenção de conhecimento, a partir da construção e percursos.

Podemos encontrar rastros de coleta de informações, por exemplo, sobre assuntos a serem tratados, sobre técnicas a serem utilizadas ou sobre as propriedades da matéria que está sendo manuseada. Dicionários, enciclopédias, recortes de jornais, revistas, livros citados e trechos copiados são documentos dessa necessidade de pesquisa. (Salles, 2012, p. 125)

Percursos estes que são também táticas de deslocamento de interesses e objetivos, como se produz na ciência: "transladar interesses significa, ao mesmo tempo, oferecer novas interpretações desses interesses e canalizar as pessoas para direções diferentes" (Salles, 2012,3 p.126).

Dessa forma, os conceitos de documento de processo e de inscrição são acionados aqui para a abordagem do tema da produção de referência na e de pesquisa em arte, e para pensarmos a inserção dessas referências produzidas em uma nova cadeia de circulação de sentidos prevista pelos projetos artísticos em gestação - não necessariamente nesta ordem. As noções de percurso e de deslocamento despertam também a reflexão sobre o progressivo adensamento das redes de relação estabelecidas com o fazer criativo - físicas, conceituais, poéticas, estéticas - que potencializadas pelas estratégias de representação empregadas, vale-se recorrentemente de cálculos de redução (simplificação) para fazer circular as informações no interior do próprio processo, e no mundo.

Seja em arte ou ciência, a produção de referência não pode se reduzir a um mero processo de tradução - uma nova imagem que se acrescenta às formas - trata-se de um procedimento mais denso, de aproximação entre pensamentos e contextos; produzir referência é uma forma de preencher lacunas, pequenas lacunas, entre as palavras e as coisas, entre a linguagem e 0 mundo.

\section{Ou como afirma Latour,}

a palavra referência aplica-se à estabilidade de um movimento ao longo de inúmeras mediações e implementos diferentes. (...)Todavia, se a referência é aquilo que circula pela série inteira, toda mudança em qualquer elemento da série provocará outra na referência.(Latour, 2001, p.176)

\section{E acrescenta:}

(...) com as proposições, ninguém precisa ser tão avaro e a sofisticação pode ser dividida igualmente entre todos os que contribuem para o ato de referência. Não tendo de preencher uma imensa e radical lacuna entre duas esferas, mas apenas transitar por inúmeras lacunas menores entre entidades ativas ligeiramente diferentes, a referência já não é uma correspondência na base do tudo-ou-nada. (Latour, 2001, p.173)

Salles fala sobre a produção de referência na arte a partir do estudo dos documentos de processo. Por este viés, segundo a autora, a ideia da pesquisa, poderia ser constatada a partir de duas grandes constantes que acompanham o movimento de produção da obra: armazenamento e experimentação. $O$ primeiro termo refere-se aos recursos e meios de registro empregados pelo artista para guardar as informações, de modo a poder reacessá-las em momentos diferentes do percurso investigativo, e o segundo é por onde transparece a natureza indutiva da criação, no sentido peirceano do termo.

Queremos enfatizar que o ato de armazenar é geral, está sempre presente nos documentos de processo. (...) Outra função desempenhada pelos documentos de processo é a de 
registro de experimentação, deixando transparecer a natureza indutiva da criação. Nesse momento de concretização da obra, hipóteses de naturezas diversas são levantadas e vão sendo testadas.(Salles, 2012, p.18)

A partir de uma abordagem relacional entre estes documentos de processo e os artefatos apresentados (os diagramas, apresentados enquanto obras) é suscitada uma reflexão sobre o processo do fazer arte pelo viés do modelo de rede e ancorado nos procedimentos do design: como um processo contínuo de interconexões instáveis, pela geração de nós de interação, cuja variabilidade obedece a alguns princípios direcionadores. Para Salles, a vantagem desta estratégia é a possibilidade de se compreenderem as interconexões produzidas pelo artista a partir das relações que estabelece com seu espaço e seu tempo, por meio de questões relativas à memória, à percepção, aos recursos criativos que definem os diferentes modos de estruturar as tramas do pensamento em criação.

Para Latour, esta noção está associada à ideia de inscrição, termo empregado por ele para descrever, em geral, todos os tipos de transformação que "materializam uma entidade num signo, num arquivo, num documento, num pedaço de papel, num traço"( Latour, 2001,p. 176) para ele as inscrições são quase sempre bidimensionais e conferem a possibilidade de "superposição e combinação, além de sua natureza móvel, permitindo novas translações, articulações, mantendo intactas, apesar disso, algumas de suas formas relacionais".(Latour, 2001, p. 176)

Dois autores que trazem duas formas distintas de se olhar para o movimento de produção de referência, de aspectos informacionais das pesquisa, o uso de esquemas no processo de pesquisa na arte, noções que nos auxiliam no relato da apropriação dos diagramas em proposições artísticas bastante distintas, mas que, a partir dessas leituras de seus processos de produção referencial, nos permitem uma aproximação maior e um espaço comum entre fazer pesquisa e fazer arte.

\section{Diagrama}

Os documentos de processo e as inscrições são construções que ajudam a pensar os processos de pesquisa em arte, por um viés não somente representacional, e o estabelecimento de conexões entre recursos projetuais e proposições poéticas. Como explorar, por dentro e de perto, as diversas e múltiplas versões do social produzidas pelas redes acionadas pelas pesquisas aqui apresentadas?

A partir desta questão, propomos uma abordagem do diagrama como estratégia de compor constelações (saberes, perceptos e práticas), para desterritorializar a noção de social como dimensão estática, bem como relativizar qualquer significado a priori para qualificar os objetos das pesquisas apresentadas: as "zonas de engate" e a "cidade-dormitório". Neste sentido, os gráficos apresentados, mais do que uma compilação visual dos conteúdos gerados durante o trabalho de campo, potencializam uma discussão sobre a construção de referência de pesquisa em arte, sobretudo para lidar com a inextrincável combinação dos microprocessos que engendram as investigações, para a identificação destes microprocessos e para compreender como eles estão inter-relacionados e implicados uns nos outros.

A ferramenta de visualização de dados (Raw Graphs) ${ }^{2}$ é empregada para mapear acontecimentos gerados a partir de vivências na cidade e se faz pelo viés de uma liturgia desviante dos mecanismos de padronização e de controle, para os quais estas ferramentas, por vezes, parecem vocacionadas. É nesse sentido que os gráficos potencializam-se como ferramentas criativas; para criar contextos de emergência de novos procedimentos investigativos e para ampliar os espectros referenciais da pesquisa.

Neste sentido, o diagrama não alude somente ao campo da representação, na medida em que são explorados pela realidade e concretude que lhes são próprias. Por este viés, são abordados, ao mesmo tempo, como esquemas de entendimento (artefato gráfico) e como

\footnotetext{
${ }^{2}$ RAW Graphs é uma estrutura de visualização de dados de código aberto construída com o objetivo de facilitar a representação visual de dados complexos). Disponível em: <http://rawgraphs.io/about/>. Acesso em: 22/04/2019
} 
processo gerativo da pesquisa (dispositivo conceitual), ou seja, para auxiliar na sistematização de processos já iniciados e para a proliferação de novos processos (mapa de movimento).

No primeiro caso, o diagrama apresenta-se por viés retrospectivo, no segundo por um viés projetivo. Sendo assim, o diagrama como artefato, torna-se uma estratégia representacional, empregada para trazer à vista informações que não estão explicitadas ainda na pesquisa. Como processo gerativo, o diagrama mostra-se como um dispositivo de formação da pesquisa, empregado para tramar novas associações entre processos, proposições e as múltiplas versões do social potencializadas e produzidas a partir das ações poéticas-investigativas.

Ou seja, o diagrama, como é apropriado pelas experimentações, define estratégias para construir esquemas abstratos a partir da concretude das relações com os lugares, pessoas, acontecimentos, como se estabelecem diretamente, para gerar novos processos gerativos e demarcar novos espaços possíveis para a pesquisa.

Na visão de Nikolaus Gansterer, estas duas dimensões do diagrama - representativa e virtualizante - de fato não se conflituam, "pois seria inerente a ele uma certa oscilação entre sistematização e abertura: um jogo entre ordem-estabilidade e desestabilização-descoberta". (Gansterer, 2011, p. 31)

O autor toma como exemplo as estruturas de vigilâncias específicas do panóptico, segundo Foucault, como tradução prototípica desta noção de diagramas, na medida em que estabiliza estruturas particulares para fazer cumprir uma funcionalidade do mecanismo disciplinar: define pelo viés de formas de uma construção arquitetônica uma tecnologia política que pode ser implementada em outros espaços. (Gansterer, 2011, p. 32)

Pelo viés do diagrama, buscamos a materialização das linhas que conectam os sujeitos às ocorrências que definem a cidade, para a concepção de espaço euclidiano - o espaço percebido por um ponto de vista autoral - em sua perspectiva formal, para uma concepção espaço topologicamente definido - em que o ponto de identificação do espaço depende estritamente de uma posição relacional.

\section{Diagrama como esquemas de entendimento: artefato}

$\mathrm{O}$ termo artefato remete à dimensão material do diagrama e às suas propriedades formais. Tais atributos estão articulados neste relato pelo viés do conceito de topologia ${ }^{3}$, a partir da identificação de entidades que podem render percepções e ações, para questionar aquilo que nos parece, à primeira vista, comum e corriqueiro.

Segundo Michael Hoffmann (2013) no contexto da arquitetura, o diagrama mostra-se como uma alternativa gráfica para articular formas sentenciais e algébricas (matemática, lógica) e também para apresentar as relações entre proposições lógicas e poéticas, para a operacionalização de um pensamento diagramático, sobre o qual se ancoram os processos de projeto arquitetônico. Trata-se de uma forma de pensamento presente também na constituição dos processos da arte pelo viés do design, no caso, para a operacionalização de estratégias de construção da pesquisa.

"Como formas de cognição distribuída, o pensamento diagramático, estaria ancorado na construção de representações externas baseadas em regras e convenções de um sistema de representação". (Hoffmann, 2013, p.101)

Para Jakub Zdebik (2012), o plano, o mapa e o gráfico seriam as formas básicas para a compreensão e produção dos diagramas: "Um plano representa uma construção que ainda não foi construída, um mapa representa terras que ainda não viajamos e os esquemas (gráficos) mostram as relações entre variáveis" (Zdebik, 2012, p.71). No caso, estes elementos são empregados para inferir modos de materialização de pensamentos-processos do artista, assim como aplicado em outras áreas de conhecimento, no sentido de "facilitar os processos de pensamento, individuais ou sociais, em situações complexas demais para serem conduzidas por meios cognitivos internos" (Hoffmann , 2012, p. 102).

\footnotetext{
${ }^{3} \mathrm{O}$ ramo da matemática que lida com a estrutura lógica do espaço - do grego topos (local) e logos (estudo racional e coerente).( VASSÃO, 2010, p. 45).
} 
A ideia de diagrama como esquemas de entendimento, facultaria uma dimensão projetiva do fazer arte, "um instrumento capaz de registrar, acompanhar e induzir processos e relações, estruturar informações, incorporar o tempo à forma, mapear e investigar o próprio processo de projeto" (Sperling, 2013, p. 36).

Ao longo das experimentações realizadas nas disciplinas, os diagramas são estratégias de representação aplicadas para a espacialização de saberes de comunicação. Dispositivo empregado para lidar com a materialidade dos processos criativos-investigativos, pelo viés abstrações (redução), com o objetivo de dar visibilidade aos espaços tramados pelas ações poéticas-investigativas. Pelo viés de composições imagéticas (representações), buscamos interfaces materiais (gráficos) que liguem os espaços concretos e virtuais das pesquisas: mediação entre processos, materialidades, corpos, dispositivos tecnológicos, repertórios e ações.

\section{Diagrama como dispositivo conceitual: processo gerativo}

Como processo gerativo, o diagrama já não é mais o gráfico, ou qualquer outra configuração visual que apresente ocorrências particulares da pesquisa, mas uma metodologia capaz de lidar com os eles e torná-los referência de pesquisa. Neste sentido, como processo gerativo, o diagrama torna-se uma forma de lidar com a materialidade da pesquisa e, ao mesmo tempo, compreender uma dimensão que escapa ao esquema, para fazer trafegar dimensões imateriais do social nas dimensões imateriais dos processos poéticos e investigativos, e vice versa. Como lidar com as novas relações de forças que emergem das conexões entre os muitos e múltiplos microprocessos que emergem das práticas de pesquisa na arte?

Em torno desta questão, buscamos os diagramas como estratégia poética, ou modo de lidar com as paisagens ruidosas da cidade - porque são elas forjada por múltiplos regimes semióticos - e para enfrentar as flutuações epistemologias e conceituais que envolvem o fazer pesquisa em arte.

Neste sentido, aproximamo-nos do conceito de diagrama oferecido por Ricardo Basbaum (2007), como um dispositivo poético-investigativo que opera a incorporação de processualidades no fazer artístico: "um amplo aporte operativo e conceitual que possibilita relacionar pensamento, representação e exterioridade; sobretudo para intervir na formação do projeto de arte. Ou ainda, segundo Nikolaus Gansterer (2011), que faz do desenho como um meio de pesquisa que permite o surgimento de novas narrativas e idéias, rastreando o potencial especulativo dos diagramas.

Recorremos, portanto, ao diagrama como estratégia conceitual - cujos fundamentos estão tramados nas fronteiras dos pensamentos do design e da filosofia - para evidenciar (contemplar) não somente a forma, mas o que vai dentro da informação que o diagrama transporta. Os efeitos dos deslocamentos que estes diagramas promovem podem resultar na produção de conceitos e processos de subjetivação, sem abrir mão das articulações que emergem da percepção das formas, para estabelecer correlações sociais.

No contexto do fazer arte, as experiências cognitivas, as cadeias de pensamentos e de ações não estão dissociadas de uma materialidade. Os sentidos do social que se adensam, a partir dos diagramas, tomam novos contornos no contexto da pesquisa em arte. O diagrama, empregado como mecanismo para fazer circular proposições precárias, não se fundamenta no objetivo de quantificar dinâmicas da cidade, mas identificar territórios possíveis. Em torno do proposito de poder lidar com as paisagens ruidosas da cidade, as experimentações investem na multiplicidade dos gráficos, para a constituição de vínculos e para traçar territórios comuns entre poéticas e urbanidades.

Pelo viés dos diagramas, elaboramos estratégias de redução (abstração) para relacionar proposições (poéticas) e espaços. Os relatos que seguem são propostas de diagramas que investem na mistura de conceitos, micro processos e formas gráficas para lidar com as diferenciações, tornando pertinentes ocorrências aparentemente inúteis, tornando audíveisvisíveis ocorrências inauditas. 


\section{Experimentações}

\section{Pathos $^{4}$ (Cartografia Afetiva): As zonas de engate.}

O conceito de "inscrição" em consonância com a produção de documentos de processo, mostra-se como fundamento para uma cartografia dos afetos estabelecidos no cotidiano do contexto da pesquisa Pathos (Cartografia Afetiva); um projeto poético cujo objetivo é aproximar qualitativamente modelos de relação que são produtos dos jogos de forças travados em diferentes redes de dispositivos usados para promover encontros eróticos-afetivos. Zonas de engate é a expressão empregada para identificar os pontos de acesso urbanos que possibilitam relações sexuais entre homens: locais como casas-de-banho públicas, saunas, darkrooms, locais indicados para encontros sexuais fortuitos.

$\mathrm{Na}$ qualidade de documentos de processo, cada uma das inscrições que compõem a cartografia representam um percurso de, não apenas armazenamento das informações referentes aos encontros, mas um trajeto de experimentação, à medida que a incorporação de diferentes linguagens ao processo de produção referencial implica, consequentemente, na adjunção de códigos múltiplos ao projeto poético em andamento. Os encontros na cartografia são quantificados e qualificados a partir de uma série de informações, referentes às particularidades de cada acontecimento. Em seguida, essas informações são encapsuladas na forma de categorias, tal qual micro sistemas integrantes de um sistema maior, representado aqui pelo complexo total da tabela de dados (Fig. 1).

Figura 1: Tabela de dados, 2017. Fonte: Acervo documental Marcio Peixoto

\begin{tabular}{|c|c|c|c|c|c|c|c|c|}
\hline & A & B & c & D & E & $F$ & G & $\mathrm{H}$ \\
\hline 1 & SUJETTOS & ANO & MES & DIA & Dispositivos ("Facilitadores") & Natureza do Encontro & Intensidade Sexo-Afetiva & Parceiros \\
\hline & & & & & & & & \\
\hline 3 & OUTUBRO & & & & & & & \\
\hline 4 & $=0$ & 2016 & 10 & 4 & Dasing & Casual & 3 & Conhecido \\
\hline 5 & $=$ & 2016 & 10 & 4 & Dasing & Casual & 1 & Conhecido \\
\hline 6 & $=$ & 2016 & 10 & 8 & Dasing & Casual & 3 & Desconnecido \\
\hline 7 & $=1$ & 2016 & 10 & 15 & Cruising & Marginal & 2 & Desconhecido \\
\hline 8 & 10 & 2016 & 10 & 17 & Dating & Casual & 1 & Conthecido \\
\hline 9 & $=$ & 2016 & 10 & 19 & Cruising & Marginal & 3 & Conhecido \\
\hline 10 & $=1$ & 2016 & 10 & 19 & Cruising & Marginat & 2 & Desconnecido \\
\hline 11 & $=$ & 2016 & 10 & 20 & Crising & Marginal & 3 & Desconhecido \\
\hline 12 & $=0$ & 2016 & 10 & 23 & Outing & Circunstancial & 1 & Contrecido \\
\hline 13 & 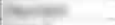 & 2016 & 10 & 23 & Dasing & Casual & 3 & Contrecido \\
\hline 14 & $=1$ & 2016 & 10 & 26 & Cruising & Marginal & 2 & Desconhecido \\
\hline 15 & $1=$ & 2016 & 10 & 27 & Outing & Circunstancial & 1 & Connecido \\
\hline 16 & $=$ & 2016 & 10 & 31 & Dasing & Casual & 3 & Conhecido \\
\hline & NOVEMBRO & & & & & & & \\
\hline 18 & $=0$ & 2016 & 11 & 1 & Outing & Circunstancial & 1 & Contrecido \\
\hline 19 & $=4$ & 2016 & 11 & 7 & Cruising & Marginal & 1 & Desconnecido \\
\hline 20 & $1=0$ & 2016 & 11 & 7 & Dasing & Casual & 3 & Desconhecido \\
\hline 21 & $N=$ & 2016 & 11 & 15 & Outing & Circunstancial & 3 & Conhecido \\
\hline 22 & mest & 2016 & $n$ & 22 & Ousing & Circunstancial & 1 & Conhecido \\
\hline 23 & 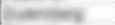 & 2016 & 11 & 26 & Outing & Circunstancial & 2 & Connecido \\
\hline 24 & $=$ & 2016 & 11 & 26 & Outing & Circunstancial & 2 & Conhecidos \\
\hline 25 & DEZEMBRO & & & & & & & \\
\hline 26 & $=$ & 2016 & 12 & 1 & Dating & Date & 1 & Conhecido \\
\hline 27 & JANEIRO & & & & & & & \\
\hline 28 & $m$ & 2017 & 1 & 10 & Cruising & Marginal & 3 & Desconhecido \\
\hline 29 & 10 & 2017 & 1 & 14 & Outing & Circunstancial & 1 & Desconheciodo \\
\hline 30 & $1=1$ & 2017 & 1 & 14 & Outing & Circunstancial & 1 & Desconhecido \\
\hline 31 & 101 & 2017 & 1 & 14 & Cruising & Casual & 2 & Desconhecido \\
\hline 32 & 10 & 2017 & 1 & 14 & Cruising & Casual & 3 & Desconhecido \\
\hline 33 & 10 & 2017 & 1 & 14 & Cruising & Casual & 4 & Desconhecido \\
\hline 34 & $1=0$. & 2017 & $i$ & 14 & Cruising & Casual & 4 & Desconnecido \\
\hline
\end{tabular}

Duas perspectivas de leitura são interessantes neste momento de pesquisa. A primeira diz respeito a representação pontual de cada encontro/relação enquanto acontecimento disposto em um período espaço/temporal. A segunda é relacionada aos dispositivos (tratados como práticas) das quais esses encontros/relações emergem, e a proporção em que foram utilizadas tais práticas no período temporal extraído da amostra cartográfica. A partir de ambas realizo, adiante, os testes com os diagramas.

Para a primeira perspectiva opto por um modelo que se estrutura em um esquema de coordenadas cartesianas, que alimentado pelos dados numéricos referentes às datas de cada encontro/relação, transforma-os em pontos, e os distribui a partir de dois eixos: $x$ e $y$, designantes, respectivamente, dos meses e dos dias referentes à amostra do período de realização da cartografia. O que ocorre aqui é uma espacialização imagética do tempo, onde a

4 Pathos: Os diagramas como estratégias para uma cartografia afetiva, por Marcio Peixoto; acesso: http://extimidades.tumblr.com.

Anais do $9^{\circ}$ Congresso Nacional de Iniciação Científica em Design da Informação | CONGIC 2019

Proceedings of the $9^{\text {th }}$ Information Design Student Conference 
partir da criação de eixos temporais, é possibilitada uma visualização geral de todos os eventos referentes à pesquisa, distribuídos e organizados cartesianamente no diagrama.

Com pouco mais de três meses do início da proposição Pathos, agregar o tempo em unidades conceituais a fim de propor modos de visualização da pesquisa é uma tarefa, que inevitavelmente perpassa a tentativa e o erro. A partir do modelo de diagrama escolhido, o gráfico de dispersão, posso atribuir valores aos pontos, representantes dos encontros sexuais e afetivos, para localizá-los dentro do esquema de coordenadas (referentes às unidades temporais - tal qual opto utilizá-las).

Nos diagramas a seguir (Fig. 2 e Fig. 3) opto por trabalhar com escalas temporais de meses (y) e dias (x), sendo os meses de Outubro, Novembro e Dezembro de 2016 os três meses dos quais disponho de dados e material cartográfico. Os pontos distribuídos no diagrama indicam os momentos em que, nos referidos espaços temporais, os acontecimentos se deram. A cor aqui não é uma variável qualitativa. O tamanho de cada ponto, no entanto, configura aqui uma variável quantitativa, à medida que representa a quantidade de encontros/relações que ocorreram no espaço de tempo designado, ou seja, no dia $x$ do mês $y$.

Figura 2: Experimento I, 2017. Fonte: Plataforma RAW.

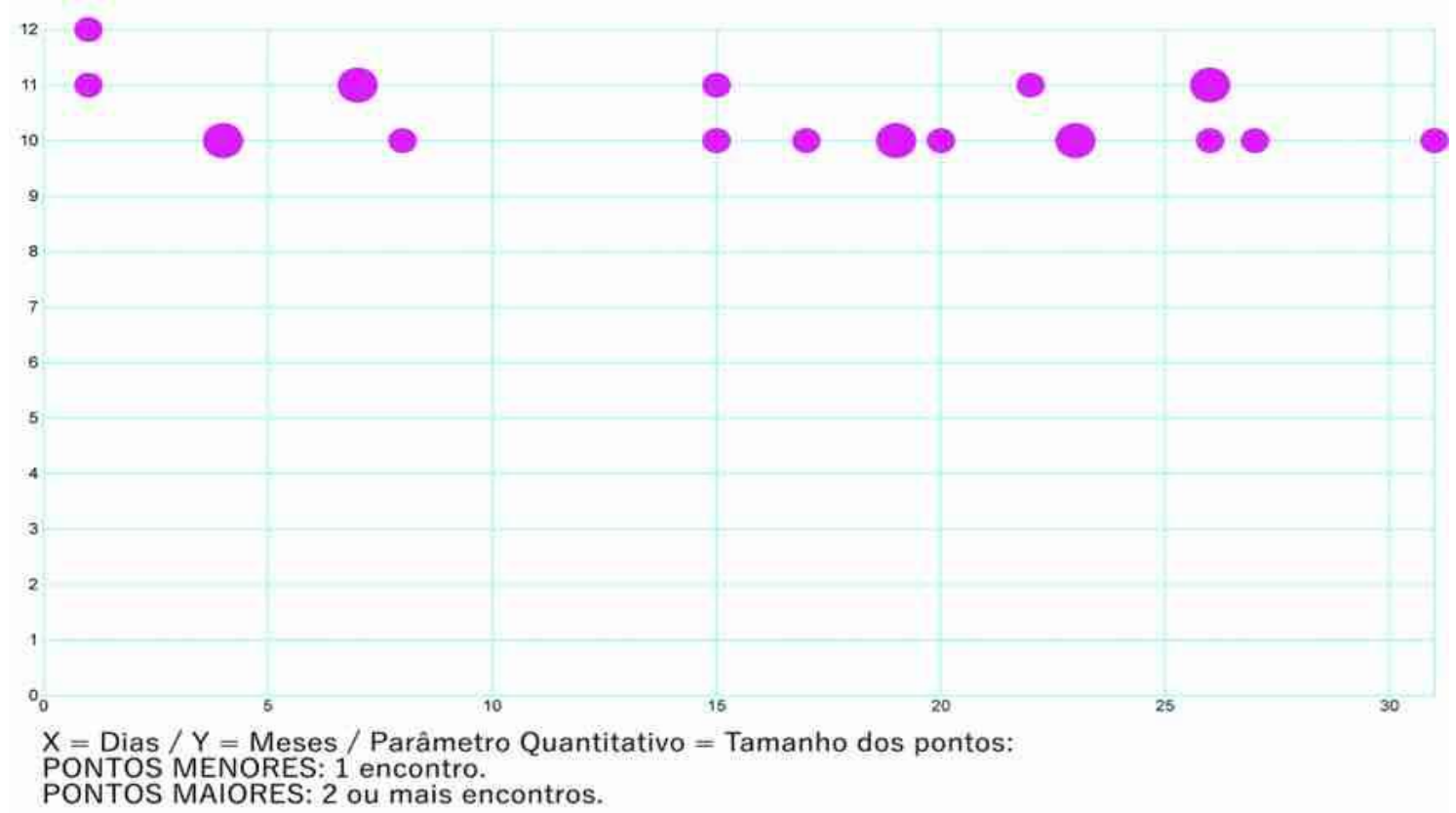


Figura 3: Experimento II, 2017. Fonte: Plataforma RAW.

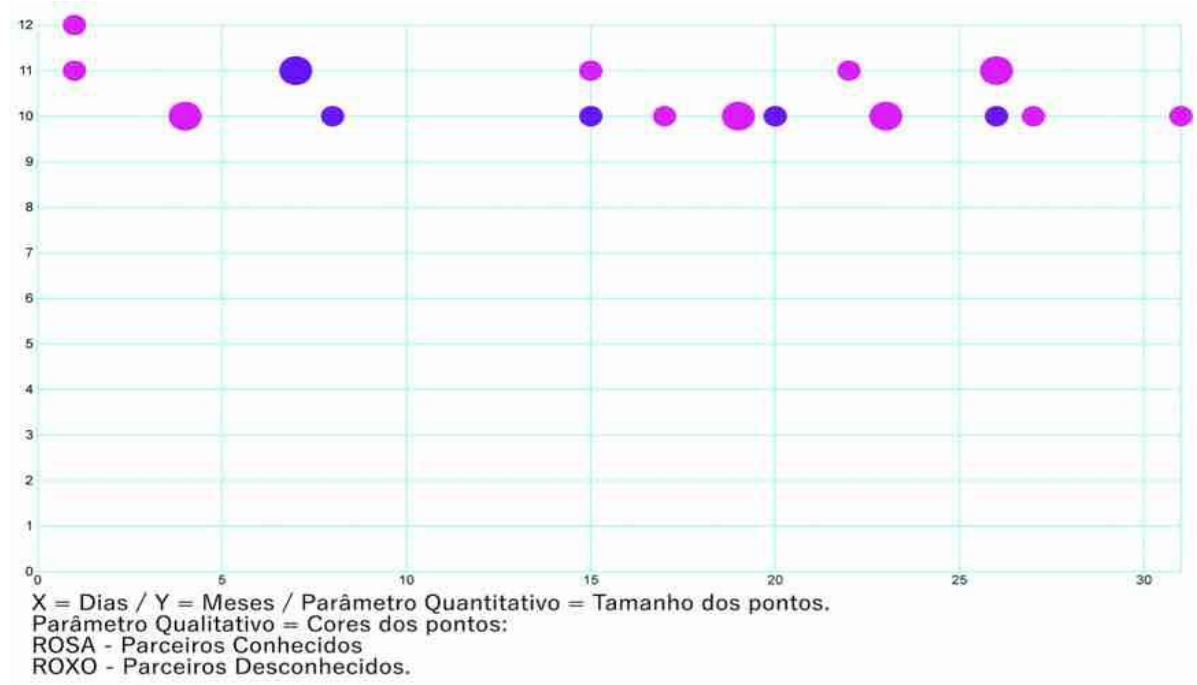

Na Fig. 3 temos o mesmo gráfico de dispersão apresentado na Fig. 2, com o acréscimo de uma variável qualitativa (designada pelo aspecto cor). Os pontos de cor mais escura (Roxo) designam os encontros e relações mantidas com interlocutores desconhecidos, ou seja, com quem eu não havia tido nenhum tipo de contato prévio ao acontecimento, já os interlocutores conhecidos são designados pela cor mais clara (Rosa).

Para ilustrar a minha segunda perspectiva utilizo fluxogramas (Fig. 4 e Fig. 5), que me permitem visualizar não os acontecimentos em específico, mas o fluxo temporal das práticas das quais eles emergem, a partir do uso de uma lista de dados contínuos que caracterizam cada um dos referidos encontros individualmente. Aqui me interessa observar as variações de intensidade entre as práticas ao longo do período compreendido pela amostra. Faço uso de dados de apenas dois meses, mas a ideia é estender esse processo cartográfico por, no mínimo, mais dez meses, para fechar assim um ano de dados a serem diagramados.

Pretendo utilizar os diagramas para a produção de múltiplos mapas referentes a períodos de tempo específicos, dispostos sequencialmente, e aos fluxos crescentes e decrescentes das práticas afetivo-relacionais. A cor é a variável escolhida para distinguir as práticas que estão, temporariamente, categorizadas como Dating (verde), Cruising (vermelho), e Outing ${ }^{5}$ (azul).

\footnotetext{
${ }^{5}$ Dating e um termo utilizado no contexto desta pesquisa para fazer referencia a um modelo de encontro caracterizado pela casualidade. O Cruising surge, neste contexto, para caracterizar as praticas afetivas de caráter marginal. O Outing e um termo utilizado aqui como um neologismo, em referencia a encontros caracterizados pela circunstancialidade.
} 
Figura 4: Experimento III, 2017. Fonte: Plataforma RAW.

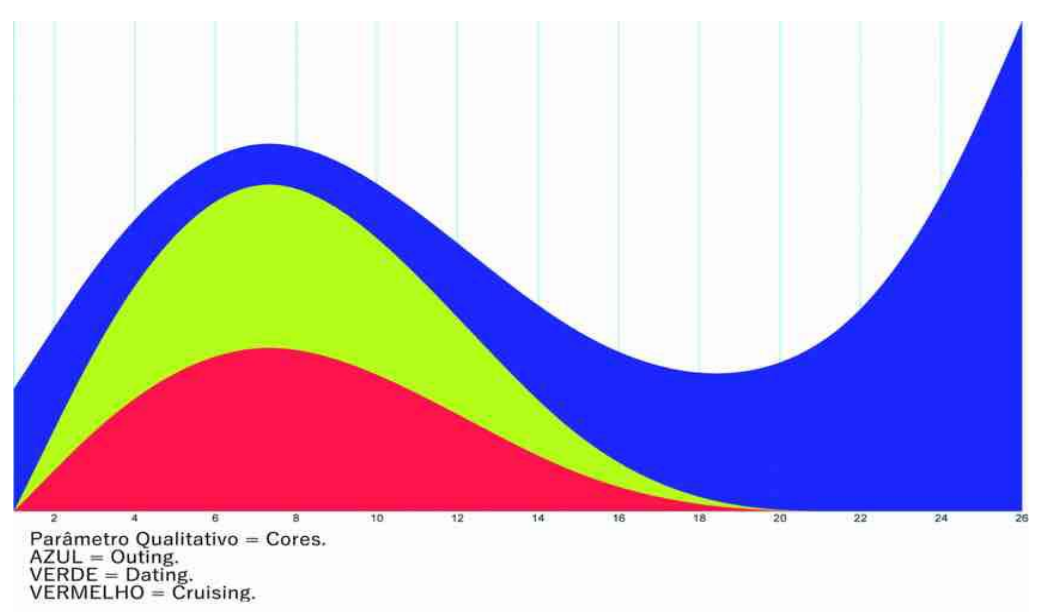

Figura 5: Experimento IV, 2017. Fonte: Plataforma RAW.

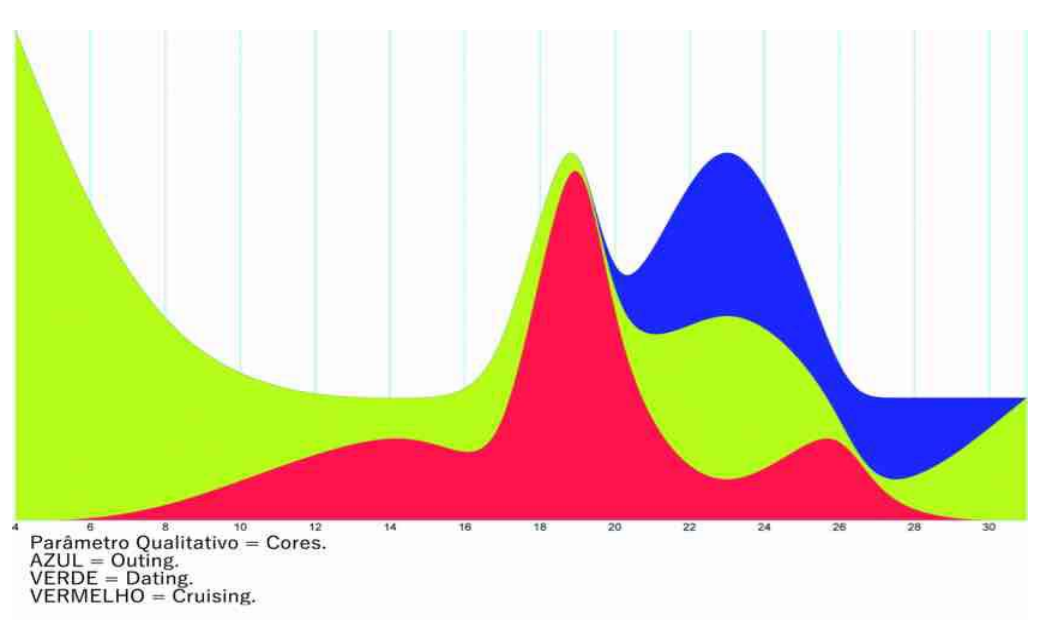

\section{Mapa de Errâncias ${ }^{6}:$ A persistência da imagem de si na cidade-dormitório}

Mapa de Errância é um projeto artístico que explora o bairro de Maracanaú (Fortaleza-CE) pelo viés das relações, vivências e memórias; envoltas pelas inquietudes criativas que despontaram em minha infância nos anos 90. Apresento experimentações sobre o uso dos diagramas (gráficos-agenciamentos) como estratégias de articulação entre tempo, espaço e ação, para qualificar o ato de fotografar a cidade .

Criei nomenclaturas que me auxiliaram nos deslocamentos pela cidade e organizar que relações seriam buscadas, para serem posteriormente evocadas em fotografia. Funcionando como um inventário, essa proposição busca, ao remexer em reminiscências, uma análise de alguns arquivos e repertórios da cidade, bem como grupos sociais e outros indivíduos de importância à pesquisa, como as personas queer. É aqui que se estabelece uma relação criativa com os diagramas, como ligação direta com o passado, a fim de percorrer uma premissa acerca das transformações étnicas e socioculturais dos habitantes de Maracanaú, remontando nisso também minha própria trajetória com a cidade.

${ }^{6}$ Mapa de Errâncias: A persistência da imagem na cidade-dormitório, por José Antonio da Silva Filho. 
Buscando qualificar minhas relações com meu lugar de ação de pesquisa criei nomenclaturas que me ajudassem a entender minha correspondência com sua extensão, bem como dessem, em algum instância uma dimensão da experiência comum vivida por outros indivíduos na cidade. Neste sentido, essa nomenclatura qualifica os lugares por onde passei, indicando também como me reaproximo deles atualmente para emergir as fotografias que são parte do processo prático dessa pesquisa.

ZONA DE INVERSÃO: São todos os lugares onde criei, em minhas primeiras vivências na cidade, uma chance única de inverter, ou mesmo subverter, a realidade presente a partir da construção de uma outra imagem que se instalasse e questionasse as funções enrijecidas no espaço. Exemplos: escolas onde estudei, locais de moradia, igrejas, lugares públicos etc. A proposição também pretende remexer arquivos, criando um inventario de memorias através da fotografia (Fig.6 e 7).

Figura 6: Zona de Inversão I, 2017. Fonte: Acervo de Pesquisa de José Antonio da Silva Filho.

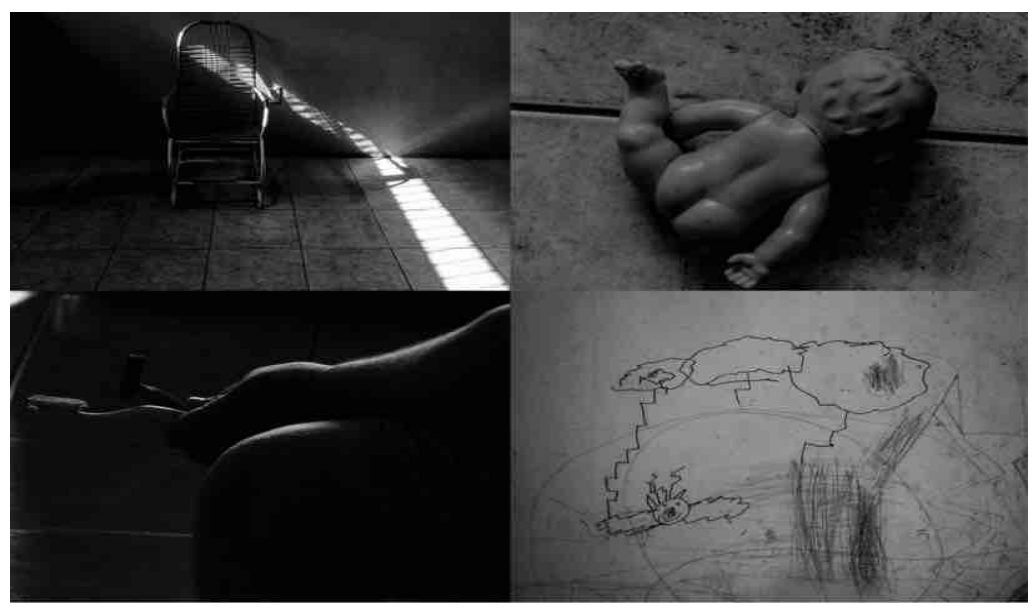

Figura 7: Zona de Inversão II, 2017. Fonte: Acervo de Pesquisa José Antonio da Silva Filho.

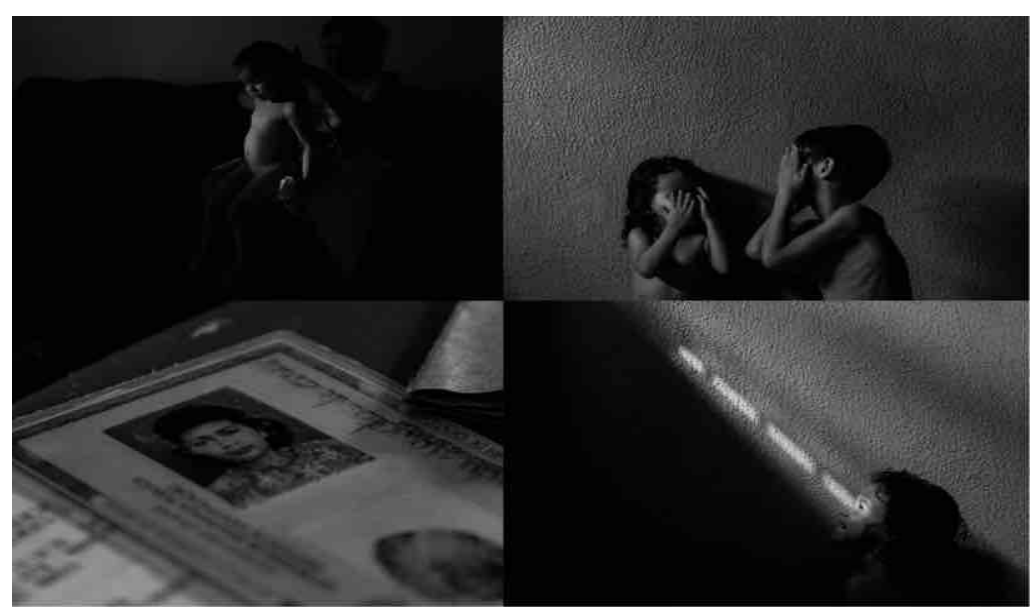

ZONA DE CISÃO: São as zonas de tensão da cidade. Lugares onde a imagem é dividida em polos, zonas de alto índices de machismo e casos de agressão à mulheres e LGBT's. Locais onde a construção e a fragmentação, de figuras e grupos vulneráveis, encontram um ponto comum para acontecerem. Exemplos: bares, restaurantes, igrejas, casas onde morei etc.

ZONA DE HORIZONTALIDADE: Os espaços de resistência, imposição e desdobramento dos indivíduos marginalizados da cidade, funcionam como um ponto de mutação.. São lugares para as narrativas possíveis e variáveis nascerem. Exemplos: bordeis, escolas, ruas e avenidas.

Relacionamos as seguintes proposições: 
MATERIAL BRUTO: Nessa proposição, o instante-presente é mapeado por uma videografia que faz um registro livre no espaço-tempo. Uma câmera na mão, que transita por festas, encontros, ruas, indivíduos e lugares. Um olhar que percorre as imagens hoje da vida em Maracanaú, ou como ela se apresenta em intensidade e espontaneidade através de seus indivíduos marginalizados.

NÃO-LUGAR: Nessa proposição, busca-se "entre lugares", em outras palavras aqueles espaços capazes de não responder mais às lógicas primárias e comuns dos espaços convencionais. Este experimento se apropria dos espaços "entres", como ônibus, lugares abandonados, prédios antigos etc., uma possibilidade de acordo sensível entre a fotografia e as corporeidades que ali se impõem.

Foram escolhidos dois gráficos que representam hierarquicamente as articulações das variáveis qualitativas da pesquisa: Inversão, Horizontalidade, Cisão; In, Não-lugar, Material Bruto. Nessas estruturas, que avançam ramificando-se, é possível ter uma noção de como e onde meu movimento se dá em Maracanaú e a partir de que relações isso acontece.

Tratando-se de gráficos hierárquicos, é possível verificar a partir das relações (Inversão, Horizontalidade, Cisão) como minha qualidade de ação se dá em cada zona (In, Não-lugar, Material Bruto), a incidência de cada uma delas e em que locais específicos as fotografias são geradas (ruas, escolas, igrejas etc.). Em ambos, os traçados fundados são impulsionados por um nó, ou pergunta-chave: como subverter a câmera e suas funções e infiltrar-se em outros sentidos de uma cidade (Maracanaú-CE), para além de sua reputação como "lugar-dormitório"?

A Fig. 8 torna visível como, tecendo fios como numa grande teia, transforma-se em referência de pesquisa a experiência prática-investigativa em Maracanaú. A proposta final é que as fotografias produzidas em campos a partir relações (Inversão, Cisão e Horizontalidade), e dos movimentos (In, Material Bruto, Não-lugar), preencham também um espaço nesse diagrama, gerando uma grande corrente de elos.

Figura 8: Mapa de Errancias 1, 2017. Fonte: Plataforma Raw.

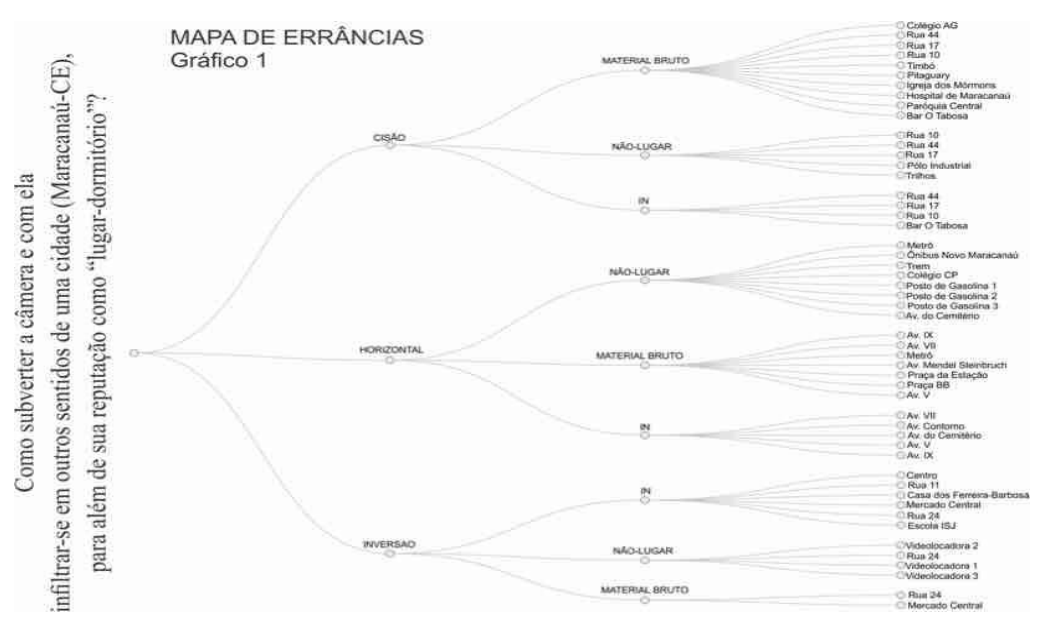

Na Fig. 9, embora semelhante ao gráfico anterior, adicionado de cores, permitem a leitura das linhas e de como elas ligam as variáveis (zona, movimento e lugar). 
Figura 9: Mapa de Errancias 2, 2017. Fonte: plataforma Raw.

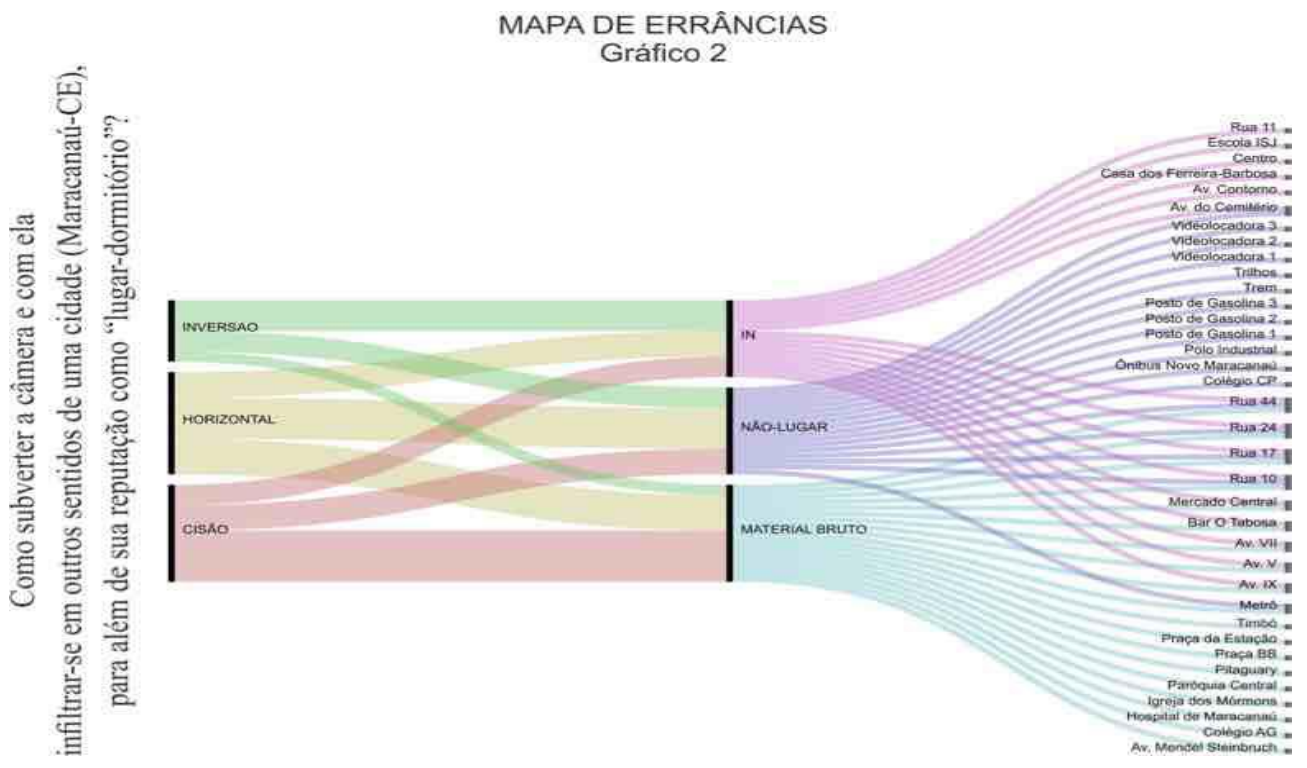

\section{Considerações possíveis}

O interesse pelas notações híbridas e pelas formas do raciocínio diagramático perpassa os estudos sobre os processos da arte e contribuem para pensar as linhas de composição das práxis artísticas no contemporâneo. O foco nas materialidades dos fazeres da arte e da ciência, como fazem Salles e Latour, naquilo que concerne tanto às vivências cotidianas quanto à invenção de métodos, conceitos e formas, aponta caminhos refletir sobre as relações entre pesquisa e arte pelo viés do como o artista apropria-se de saberes de outras áreas de conhecimento para a produção poética.

Os mundos possíveis - temporários-possíveis -, inicialmente apenas entrevistos pelas noções de cidade dormitório e zonas de engate, adensam-se nas formas dos gráficos, os quais se compõem de forma complementar aos conceitos, afetos e perceptos, para criar redes e tonar estes "mundos" visíveis e partilháveis.

Os exercícios de combinação e a estruturação de lógicas (poéticas) possibilitam uma compreensão dos diagramas como dispositivos de produção de estruturas de sociabilidade ainda não explicitadas nas tramas da cidade. No caso, para transformar o envolvimento afetivo de caráter íntimo (amoroso ou sexual) em informação - para conferir legibilidade e comunicabilidade ao projeto estético-cartográfico em construção. Ou ainda, para promover uma dimensão coletiva, familiarizada ao modo de se relacionar com a cidade (Maracanaú) pelo viés do registro fotográfico - para atribuir critérios poéticos e relacionais para os deslocamentos do artista-investigador na prática da pesquisa.

Neste sentido, o diagrama, como descrito a partir dos resultados apresentados pelas experimentações, realiza-se como dispositivo de vinculação entre poéticas e urbanidades, e ao mesmo tempo, forma de registro e de investigação poética. Neste cenário o diagrama torna-se um procedimento-método que espreita o nomadismo e a estruturação de processos singulares para a construção de pesquisa em arte. 


\section{Referências}

Basbaum, R. (2007). Além da pureza visual. Porto Alegre: Zouk.

Bonsiepe, G (2007). The Uneasy Relationship between Design and Design Research . (in) Design Research Now Essays and Selected Projects . Birkhäuser Verlag AG Basel • Boston - Berlin.

Deleuze, G., \& Guattari, F. (1995). Mil Platôs. São Paulo: Editora 34, v. 2.

Deleuze, G. (1995). Negotiations 1972-1990. Columbia New York, University Press.

Flusser, V. (2002). Filosofia da caixa preta: ensaios para uma futura filosofia da fotografia.

Rio de Janeiro: Relume Dumará, 2002. p. 51.

Gansterer, N. (2011). Drawing A Hypothesis: Figures of Thought. New York, Springer Wien.

Hoffmann, M. (2013). Cognição e Pensamento Diagramático. In: QUEIROZ, J; MORAES, (orgs.). A lógica diagramática de Charles Sanders Peirce: implicações em ciência cognitiva e semiótica. Juiz de Fora: Editora UFJF.

Latour, B. (2001). A Esperança de Pandora. Bauru, SP: EDUSC.

Lemos, André (2013). Do paradigma ao cosmograma: sete contribuições da teoria ator-rede para a pesquisa em comunicação. XII Encontro Anual da Compos, Salvador, 2013. Disponível em: <http://academia.edu/28716918/DO_PARADIGMA_AO_COSMOGRAMA._Sete_Contri buicoes_da_Teoria_Ator-Rede_para_a_pesquisa_em_comunicacao $>$. Acesso em: $11 / 05 / 17$

Meirelles, I.(2013). Design for Information: An Introduction to the Histories, Theories, and Best Practices Behind Effective Information Visualizations. Osceola, WI, USA: Rockport Publishers.

Queiroz, J; Moraes (2013), (orgs.). A lógica diagramática de Charles Sanders Peirce: implicações em ciência cognitiva e semiótica. Juiz de Fora: Editora UFJF.

Salles, C. A. (2008). Redes de criação: construção da obra de arte. São Paulo: Editora Horizonte, 2008.

Intermeios,

(2012). Gesto inacabado: processos de criação artística. São Paulo,

Sperling. D. (2013). Diagrama e processo. O diagrama como processo. In: Sigradi 2013, Valparaiso: Editorial Universidad Técnica Federico Santa María.

Vassão, C. A. (2010). Metadesign. Ferramentas, estratégias e ética para a complexidade. São Paulo: Blucher..

Zdebik, J. (2012). Deleuze and the Diagrama. London: Continum International Publishing Group.

Sobre o (als) autor(ales)

Claudia Marinho, PhD, UFC, Brasil <marinhoclufc@gmail,com>

Marcio Peixoto, ME, UFC, Brasil <marciopxt@live.com>

José Antonio da Silva Filho , ME,UFC, Brasil < tonibenvenuti@gmail.com> 